\title{
Tagging in the Development of Sexual Nomenclature and Social Organization Online
}

\author{
Patrick Keilty \\ University of Toronto \\ 140 St. George Street \\ Toronto, Ontario M5S 1 L2 Canada \\ p.keilty@utoronto.ca
}

\begin{abstract}
In this paper, I describe the ways in which interventionist forms of tagging, such as super tagging, guerilla tagging, and tag bombing within Xtube, a database of sexual representation, reveal complex social and cultural structures among members of sexual subcultures and point to the particularlity of various modes of sexual being and the relationship between those modes and particular configurations of sexual identity. Individuals who participate in super tagging do not necessarily exert significant influence over information retrieval results within a database. Instead, in Xtube, members create alternative, activist, and interventionist forms of tags for personal and social purposes. Particularly for individuals who experience non-normative desire, such tagging practices provide a means for describing and structuring feelings of difference into coherent identities and particular social forms for socio-sexual engagement and selfexploration and understanding.
\end{abstract}

\section{Keywords}

Classification, folksonomy, tagging, gender, sexuality, pornography

\section{INTRODUCTION}

In two previous essays (2012a and 2012b), I demonstrate the ways in which mechanisms of power around classifications of gender and sexuality are not always topdown or bottom-up. Instead, the weight of social discipline among members of sexual subcultures themselves helps to create these classifications, often reflecting the nomenclature of subjects and desires within sexual subcultures in a complex relationship to a dominant culture. I critically examine benchmarks in the development of

This is the space reserved for copyright notices.

Advances in Classification Research, 2012, October 26, 2012, Baltimore, MD, USA.

Copyright notice continues right here. sexual nomenclature to show how social discipline within these sexual subcultures occurs in the stabilization of nomenclature through socialization and through individual's overt intervention into each other's selfunderstanding. In the process, I reveal a complex social and cultural structure among members of sexual subcultures by drawing our attention to the particularity of various modes of sexual being and the relationship between those modes and particular configurations of sexual identity. As such, I reassess, first, a presupposition among some classification scholars that folksonomies are free of discipline allowing for their emancipatory potential and, second, the prevailing binary understandings of authority in the development of sexual nomenclatures and classifications as either top-down or bottom-up.

In the past year, I presented different versions of these essays at three separate events (2012c, 2012d and 2012e). At each event, audience members seemed most intrigued by a small aspect of my argument relating to individuals' overt intervention into each other's sexual nomenclature and selfunderstanding in tagging practices on Xtube (xtube.com), a database of sexual representation, basically youtube for pornography. Such overt intervention within Xtube often occurs when members of a particular subculture have a high level of investment in debating the boundaries and meanings of sexual and gender categories. This plays out in discussions within Xtube's wikis and within a particular image or moving image's comment or discussion section. Overt intervention also occurs through three different kinds of tagging phenomena: tag bombing, super taggers, and guerilla tagging. I mention each of these phenomena in my essays and presentations, but only in passing, assuming that such practices were fairly well known in light of gay activists' guerilla tagging practices around Rick Santorum, a former U.S. Senator from Pennsylvania and former Republican Candidate for the U.S. Presidency in 2012. However, to my surprise, few scholars had known about tag bombing and guerilla tagging, and still fewer scholars had researched such practices.

In this essay, I offer a critical examination of the ways in which such overt intervention into sexual nomenclature occurs through the use of tagging. These interventions reveal a complex social and cultural structure among 
members of sexual subcultures and point to the particularity of various modes of sexual being and self-understanding. Space limitations allow me only to sketch out the most basic analysis of these phenomena within Xtube, and as a result, I am forced to omit some of the most fruitful discussions concerning the relationship between tagging practices, modes of sexual being, and the relationship between those modes and particular configurations of sexual identity. Future scholarship should address these issues in more depth. Space limitations also force me to omit a broader discussion about the relationship between these tagging practices and theories of language, categorization, and power (Keilty 2012a).

I should immediately clarify that tag bombing, super taggers, and guerilla tagging are not the only kinds of interventionist tagging practices online. Nor are these discrete tagging practices. We can conceive of these practices both together and separately at different times. One can find numerous definitions of tag bombing in a simple Google search. For my purposes, tag bombing occurs when an individual or several individuals heavily tag a particular item (an image, a text, a moving image, a song, etc.) with a particular set of words or phrases in an attempt to influence how an algorithm determines which folksonomies predominantly provide access to those items. Super taggers are individuals who provide a disproportionately high number of tags within a particular database, in an attempt to exert outsize influence over the folksonomies used to provide access to items within that database. Guerilla tagging is often, but not always, a form of tag bombing with the explicit goal to garner political or social influence over folksonomic access to items within a database, a form of new media activism. It is unclear how much influence these practices have over the retrieval of items within large databases, except in the case of "santorum," a noteworthy incident of tag bombing that influenced the search results within major web search engines.

The "santorum" incident is perhaps the most popular incidence of super tagging. In May 2003, the columnist and gay rights activist Dan Savage held a contest among his readers to create a definition for the word "santorum" as a response to comments by then-U.S. Senator Rick Santorum that Savage criticized as anti-gay. Savage announced the winning entry, which defined "santorum" as "the frothy mixture of lube and fecal matter that is sometimes the byproduct of anal sex." He created a website (spreadingsantorum.com) to promote the definition. Some gay rights activists joined Savage's campaign and began tagging definitions and images of the frothy mixture online with the word "santorum." As a result, the definition and images became a prominent search result for Santorum's name within several web search engines. [1] The campaign had been well documented by U.S. political news outlets (Burns 2011 and Cohen 2011).
Despite the popularity of this and other incidents, virtually no research has been conducted on the practice of super tagging. A great deal of research has been conducted on folksonomies generally, and some research has been conducted on the influence that individual's tags have on how others tag within a particular database (see especially Trant 2006 and 2009). Perhaps the dearth of research around forms of super tagging occurs, in part, because it is usually very difficult for any one individual directly and significantly to influence information retrieval through super tagging. It is especially difficult for any one individual to have a significant influence over the myriad of tagging practices and retrieval results within Xtube, which claims to have a membership of 10 million people (2012). It is much easier for a super tagger to influence the tagging practices of a database with a small number of individual taggers. Indeed, Golder and Huberman (2006) find that tagging patterns stabilize as the number of individual taggers increase, a form of crowd sourcing. There are several individual accounts within Xtube that upload a great deal of content and that contribute a significant number of tags. Perhaps collectively these individual accounts have a significant influence on tagging practices within Xtube. More research should be done to determine whether super taggers in large databases collectively influence tagging practices. However, not all forms of super tagging occurs for the purpose of significantly influencing the system of information retrieval as a whole. Instead, in the case of Xtube, as I later show, forms of super tagging often occur for personal and social purposes.

\section{XTUBE'S GENDER AND SEXUAL CATEGORIES}

As I show in a previous essay (2009), Xtube attempts to provide a near instantaneous mass mediation and dissemination of sexual representation. One might argue that this wealth of images offers an emancipatory scenario whereby subjects can project their virtual selves into a seemingly endless variety of environments, and to embody an infinite number of freely chosen subject positions, roles, and desires. In doing so, we may think Xtube allows for an exploration of the self and one's identity in relation to others (indeed, reliant on others as viewers), or, in other words, an exploration of various stylistics of the self. Yet, in my analysis of the eroticization of hierarchical knowledge structures, I find:

Xtube's classification functions to guide, if not overtly discipline, subjects-both the subjects of the images and the viewer as subject. It is evidence of an environment in which desires and subject positions are produced as essential standards through a discourse of hierarchical categorization and classification. Images on Xtube are available to the viewer only through the negotiation of a coarse and elaborate typology in which subject positions are fixed and defined in relation to each other $(2009,246)$. 
Some of these "categories" (Xtube's own language) are authoritative or prescriptive, developed by Xtube's administrators. Xtube requires viewers to select between one and three categories from among more than thirty prescriptive categories to describe an image or video when uploading it to the website. Some of these prescriptive categories include Amateur, Anal, Asian, BDSM, Bisexual, Bush, Ebony, Fetish, Fursuits, Groupsex, Hardcore, Interracial, Jerkoff, Latina, Lesbian, Mature, MILF, News, Softcore, Swingers, Teens, Toys, and Voyeur. Xtube also requires that members choose whether the video is gay or straight, and whether the subject of the video is Single Man, Single Woman, Man and Man, Men and Women, Women and Women, or Transexuals. These are members' only choices, and they probably say more about Xtube's administrators than they do about a dominant culture. Members can also add a title, description, and tags, which Xtube does not predetermine. As a result of these various categorical configurations, members can perform faceted searches that mix and match any of the various categories and tags. Members can search multiple categories and tags or a single category or tag simultaneously, all of which has been hyperlinked. Keyword searches include titles and descriptions, which have not been hyperlinked.

A member's "exploration" within Xtube is always already constrained by a logic of recognizable cues that are regularized, disciplined, and stabilized according to received forms of sex and desire. Tagging occur in relation to Xtube's prescriptive categories. As such, members' gender and sexual organization is always named, regulated, and stabilized in advance, along a coarse axis of registers. Because the identity of one's gender and sexual being belongs within discernable boundaries, one might perceive that gender and sexuality are stable, regardless of whether one's feelings transgress these boundaries.

\section{TAGGING WITHIN XTUBE}

However constrained by Xtube's prescriptive categories, it is by tagging that members have some opportunity to roleplay within and against Xtube's prescriptive categories. As one might imagine, the tags reveal a highly developed and varied nomenclature and social organization. Nomenclature is not purely particularistic and idiosyncratic. It is regulated by the social conventions of language and ideology (Keilty 2012a). As such, members develop these folk taxonomies in fundamentally communal ways. Indeed, it is important to bear in mind that the purpose of these tags is to name and structure one's gender and sexual being within a broader social network. The practice of tagging one's homemade images and videos primarily occurs so that members enable others to access their representations, for the purpose of sexual arousal. In this way, members' perception, nomenclature, and identity of their own gender and sexuality are intimately tied to each other. That is, the 'power to tag' offers queer individuals a means for describing and structuring feelings of difference into coherent identities and particular social forms, and to relate those forms and identities to the way other people view them, to the way they view other people, and to the way other people view themselves, collapsing the distinction between exhibitionist and voyeur.

Participating within this social network also means that members of Xtube regulate each other's tags and, therefore, social organization. In one instance of tag bombing, members attempt to augment Xtube's rather limiting prescriptive category "transsexual" for naming the variety of transgender ways of being with tags such as "transgender," "pansexual," "transvestite," and "cross dresser." Still other members tag items subsumed under "transvestite" with particularly offensive terminology, such as "shemale," "tranny," "slut," and "sissy." The precise function each of these tags plays in social organization is difficult to determine. For example, some tags create unexpected associations and wondrous juxtapositions, such as the relation between the national identity "Japanese" and "worship," without the adjectival modification common to a syntactical relationship, resulting in some ambiguity as to the precise way in which these words interact to represent a social relation. Super taggers play no small role in creatingsexual nomenclature in Xtube. Several, though certainly not all, super taggers within Xtube are in fact pornography companies and other pornographic websites who offer teasers of their content on Xtube as a way to entice viewers to browse their own websites. As such, many items have been tagged for a particularly corporate interest. It is within and against these corporate interests that individual members on Xtube develop their own gender and sexual nomenclature.

As just one example of tag bombing and guerilla tagging, members have tagged bombed several items subsumed under "transvestite" using Spanish slang, such as "transvesti," "travestido," "transvestido," "traba," "trabuco," and "travieso/ traviesa," among others. Spanishspeaking members have seemingly uploaded many of these items, as evidenced by Spanish titles, comments, and descriptions that accompany the item. Yet in other instances, Spanish nomenclature has been used to tag a number of images and videos with English titles, descriptions, and commentary. On one level, this form of tag bombing seeks to augment English categories and tagging and offer access to items in Spanish. On another level, this tag bombing serves as a form of guerilla tagging because it seeks to displace the absolute authority of English as the language through which access to representations of sexuality and participation in Xtube's social organization occur. Furthermore, if we conceive of tagging or the folk development of nomenclature online as a form of social organization, then tagging in Spanish offers an alternative rubric for organizing the particularities and various modes of sexual being according to different cultural categories. In this instance, Spanish provides a far more particular nomenclature for identifying transgender ways of being, each slang word signifying a different 
meaning or inflection that does not necessarily directly correspond to an English equivalent.

This has considerable potential for the average viewer. Suppose a viewer finds desirable a particular image tagged "trabuco," s/he can click on the tag, which has been hyperlinked, to discover a wide variety of related items s/he may also find desirable. In doing so, s/he has named her desire in a more specific way than simply "transvestite"-a specific English category that Xtube misappropriates to describe a broad range of transgender ways of being. Particularly for individuals who experience non-normative desire, naming provides a means for describing and structuring feelings of difference into coherent identities and particular social forms, and to relate those forms and identities to the way other people view them, to the way they view other people, and to the way other people view themselves. As such, new social forms of gender and sexual non-conformity emerge, creating alternative ways for one to organize, understand, differentiate, and name gender and sexual relations. In a society that seeks gender and sexual conformity, organizing and structuring feelings of difference, as part of the 'power to name,' helps individuals resist social opprobrium and gives them strength to publically defy social convention through identification, and, in no small way, through the act of finding representations of one's desire and engaging sexually with those representations.

\section{CONCLUSION}

Instances of tag bombing, super tagging, and guerilla tagging on Xtube suggests that folksonomic organization of sex and desire reveal complex social and cultural structures among members of sexual subcultures and point to the particularlity of various modes of sexual being and the relationship between those modes and particular configurations of sexual identity. Individuals who participate in such interventionist forms of tagging do not necessarily significantly influence the overall results of information retrieval, particularly in large databases. Instead, in the case of Xtube, these tagging practices provide alternative avenues for retrieving items, for sociosexual engagement, and for sexual self-exploration. This paper offers a further illustration of the extent to which gender and sexual boundaries are culturally constructed, and it reminds us that attempts at the demarcation of those boundaries are a central aspect in the study of gender and sexual knowledge organization.

\section{ACKNOWLEDGMENTS}

I owe special thanks to Jonathan Furner and Lynne Howarth for their insights into various forms of tagging.

\section{NOTES}

[1] Savage is also widely known for the It Gets Better Project, found at itgfetsbetter.org.

\section{REFERENCES}

Burns, A. (2011). Santorum contacted Google, says company spreads 'filth'. Politico, September 20, 2011. Retrieved November 10, 2012 from http://www.politico.com/news/stories/0911/63952.html.

Cohen, N. (2011). Dealing with an identity hijacked on the online highway." New York Times, September 25, 2011. Retrieved November 10, 2012 from http://www.nytimes.com/2011/09/26/business/media/an -identity-hijacked-on-the-online-highway.html?_r=0

Golder, S. and Huberman, B. (2006). Usage patters of collaborative tagging systems. Journal of Information Science 32: 198-208.

Keilty, P. (2012a). Sexual boundaries and subcultural discipline. Knowledge Organization 39(6) (in press).

Keilty, P. (2012b). Tagging and sexual boundaries. Proceedings of the $2^{\text {nd }}$ Milwaukee Conference on Ethics of Information Organization. Spec. issue of Knowledge Organization 39(5), 320-324.

Keilty, P (2012c). Tagging, sexual boundaries, and social discipline. Paper presentation at the SIG-CR Workshop at ASIST 2012 Annual Meeting - Baltimore, MD (October 26, 2012).

Keilty, P (2012d). Sexual boundaries and social disapprobation. Paper presentation at the Conference on Ethics of Information Organization - Milwaukee, WI (June 15, 2012).

Keilty. P. (2012e). Sexual boundaries and subcultural disapprobation. Job talk at the University of Toronto (May 25, 2012).

Keilty, P (2009). Tabulating queer: Space, perversion, and belonging. Knowledge Organization 36(4), 240-248.

Trant, J. (2006). Social classification and folksonomy in art museums: Early data from the steve.museum tagger prototype. In Proceedings of the 17th Workshop of the American Society for Information Science and Technology Special Interest Group in Classification Research 17, Austin, TX.

Trant, J. (2009). Tagging, folksonomies, and art museums: Early experiments and ongoing research. Journal of Digital Information $10 \quad$ (1): http://journals.tdl.org/jodi/index.php/jodi/issue/view/65

Xtube. 2012. About us - Xtube.com. Retrieved November 17, 2012 from http://support.xtube.com/index.php?/Knowledgebase/Ar ticle/View/1891/351/about-us 